\title{
An engraved artifact from Shuidonggou, an Early Late Paleolithic Site in Northwest China
}

\author{
PENG Fei $^{1,2}$, GAO Xing $^{1 *}$, WANG HuiMin ${ }^{3}$, CHEN FuYou $^{1}$, LIU DeCheng $^{1} \&$ PEI ShuWen ${ }^{1}$ \\ ${ }^{1}$ Laboratory of Human Evolution, Institute of Vertebrate Paleontology and Paleoanthropology, Chinese Academy of Sciences, \\ Beijing 100044, China; \\ ${ }^{2}$ Graduate University of the Chinese Academy of Sciences, Beijing 100049, China; \\ ${ }^{3}$ Institute of Archaeology of Ningxia Hui Autonomous Region, Yinchuan 750001, China
}

Received February 15, 2012; accepted May 18, 2012; published online July 2, 2012

\begin{abstract}
Cognition and symbolic thinking are viewed as important features of modern human behavior. Engraved objects are seen as a hallmark of cognition and symbolism, and even as evidence for language. Accumulated evidences including engraved bones, ochre, ostrich eggshells and stone artifacts were unearthed from Africa, Europe, Levant even Siberia Paleolithic sites. But the archaeological evidence for this, including beads, ornaments, burials, performed objects and engraved objects, is rarely discovered in the Pleistocene of East Asia. The present paper reports an engraved stone object unearthed in the Early Late Paleolithic levels about $30 \mathrm{ka} \mathrm{BP}$ at the Shuidonggou site (SDG) in northwestern China. It was unearthed in the 1980's excavation from Lower culture unit of SDG1 but was identified in 2011 when the first author of this article observed the collection from the 1980's excavations stored in the Institute of Archaeology of Ningxia Hui Autonomous Region for further detailed lithic analysis. This lithic artifact is the first engraved non-organic object of the Paleolithic period found in China. In order to clarify the details of the incisions and to document the human intentional modifications, we used a KEYENCE VHX-600 Digital Microscope to measure and observe all the incisions in 3-dimensional perspective. Comparing the natural cracks and analyzing many details of the incisions, we argue that incisions on this stone artifact are the result of intentional behaviors by ancient humans. Also, we exclude the possible other causes including animal-induced damages, post-depositional phenomenon and unintentional by-products. Combining all these features, we suggest that the incisions were made by an intentional behavior and were probably of a non-utilitarian character. Because the nature of most other engraved objects in China is debate, we cannot get a clear scenario of the emergence and progress of modern human behavior in North China. But we infer the possible existence of a counting or recording system, or other symbolic behaviors, which reflect considerably evolved cognitive capacities or modern human behavior in the Early Late Paleolithic of East Asia.
\end{abstract}

modern human behavior, engraved artifact, cognition and symbolism, Shuidonggou, Early Late Paleolithic

Citation: Peng F, Gao X, Wang H M, et al. An engraved artifact from Shuidonggou, an Early Late Paleolithic Site in Northwest China. Chin Sci Bull, 2012, 57: 4594-4599, doi: 10.1007/s11434-012-5317-6

In the debates about the origin and dispersal of modern human behavior, engraved objects are usually considered as one of the most important feature of behavioral modernity [1-3]. They are seen as a hallmark of cognition and symbolism, and even as evidence for language [4-6]. Growing numbers of engraved bones, ochre, ostrich eggshells and stone artifacts are reported from South Africa, Europe and

*Corresponding author (email: gaoxing@ivpp.ac.cn) the Levant, and even North Asia palaeolithic sites [7-13]. However, in East Asia, the frequencies of engraved objects in the Pleistocene are argued to be rather low [14-17].

The present paper reports an engraved stone artifact from an Early Late Paleolithic [18] level in the Shuidonggou site, which is located in Lingwu, an outlying county of Yinchuan City, Ningxia Hui Autonomous Region. It is about $18 \mathrm{~km}$ east of the Yellow River. The site includes 12 localities, which range from Early Late Paleolithic to Late Late Paleo- 
lithic in date [19-21]. Among all these localities, locality 1(SDG1), the first discovered Paleolithic site in China, is distinctive in the Late Paleolithic Industry of North China due to its large components of elongated blank production and Levallois-like technology. In the 1920s, 1960s and 1980s, four times of excavation were carried out in SDG1 and yielded numerous stone artifacts, ostrich beads and hearths. Most of these materials have been reported in several monographs and papers $[19,22,23]$. We note that when analyzing the materials unearthed in the 1920's excavations, Breuil observed some parallel incisions on the surface of siliceous pebbles. He inferred that these incisions were made by burins [22]. Unfortunately, he did not provide more details about those incised pebbles.

In August 2011, for further detailed lithic analysis, the first author of this article observed the collection from the 1980's excavations stored in the Institute of Archaeology of Ningxia Hui Autonomous Region. The item reported here was found during this study. This lithic artifact is the first engraved non-organic object of the Paleolithic period found in China. The discovery also verifies the earlier observations of Breuil.

\section{Chronology and lithic industry of SDG1}

A series of multidisciplinary studies of the stratigraphy and environment of the Shuidonggou site have been reported [24-28]. From an archaeological perspective, the stratigraphy of SDG1 can be divided into two culture units (Figure 1). The gravel level in the middle of the profile including layers 1 and 2 belongs to the Holocene and comprises the Upper Culture Unit. The second, underlying gravel level including layers 3-7 is termed the Lower Culture Unit that dates to the Late Pleistocene. The engraved artifact is from the Lower Culture Unit. Systematic chronological work suggested that the age of the SDG1 Lower Culture Unit is about 30000 a BP [19,27-29] (Table 1). However, in August of 2011, during observation of the stratigraphic profile, we collected a charcoal sample from the upper part of the Lower Culture Unit and submitted it to the Center for Applied Isotope Studies, University of Georgia, USA for AMS ${ }^{14} \mathrm{C}$ dating. The new result shows the age of the Lower Culture Unit is $36200 \pm 140$ a BP before calibration. Although it is the only ${ }^{14} \mathrm{C}$ data before 30000 a BP for SDG1, in combination with the U-series age from the same Unit [30], it sheds some light on the possible chronological range of SDG1.

More than 6700 lithic artifacts and 63 pieces of mammalian fossil representing 15 species were unearthed from SDG1 in the 1980's excavation; approximately 5500 lithic artifacts were from the Lower Culture Unit [19]. The focus of the lithic reduction processes was the manufacture of elongate flakes and blades using Levallois recurrent technology. The tool-kit consists of scrapers, points, burins,

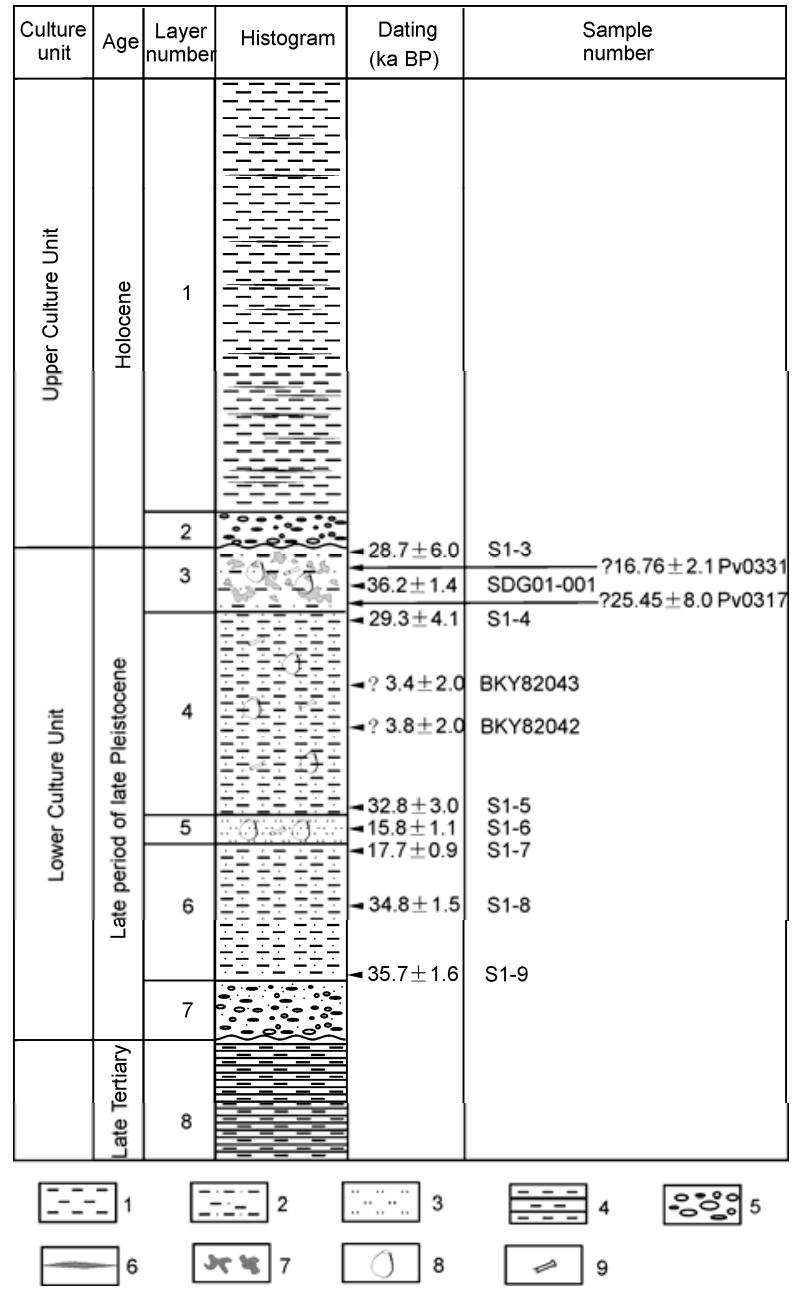

Figure 1 Stratigraphy and chronology of the Shuidonggou site (after [28]). 1, Clay-rich silt; 2, silt; 3, fine sand; 4, mudstone; 5, gravel; 6, peat band; 7 , carbonate nodule; 8 , stone artifact; 9 , animal fossil.

Table 1 Age for SDG1 Lower Culture Unit

\begin{tabular}{lcccc}
\hline Material & $\begin{array}{c}\text { Dating } \\
\text { method }\end{array}$ & Lab code & Age (a BP) & Reference \\
\hline Sediment & OSL & S1-3 & $28700 \pm 600$ & {$[28]$} \\
Sediment & OSL & S1-4 & $29300 \pm 400$ & {$[28]$} \\
Sediment & OSL & S1-5 & $32800 \pm 300$ & {$[28]$} \\
Sediment & OSL & S1-6 & $15800 \pm 1100$ & {$[28]$} \\
Sediment & OSL & S1-7 & $17700 \pm 900$ & {$[28]$} \\
Sediment & OSL & S1-8 & $34800 \pm 1500$ & {$[28]$} \\
Sediment & OSL & S1-9 & $35700 \pm 1600$ & {$[28]$} \\
Calcium nodule & ${ }^{14} \mathrm{C}$ & PV0317 & $25450 \pm 800$ & {$[29]$} \\
Cervus bone & ${ }^{14} \mathrm{C}$ & PV0331 & $16760 \pm 210$ & {$[29]$} \\
Equus teeth & U-series & BKY82042 & $38000 \pm 200$ & {$[30]$} \\
Equus teeth & U-series & BKY82043 & $34000 \pm 200$ & {$[30]$} \\
Charcoal & ${ }^{14} \mathrm{C}$ & SDG01-001 & $36200 \pm 140$ & UGAMS \\
& & & & report \\
\hline
\end{tabular}

choppers, and denticulates; among them, side-scrapers are the dominant tool type (Figure 2). Detailed techno-economic analysis will be presented in a separate publication. 

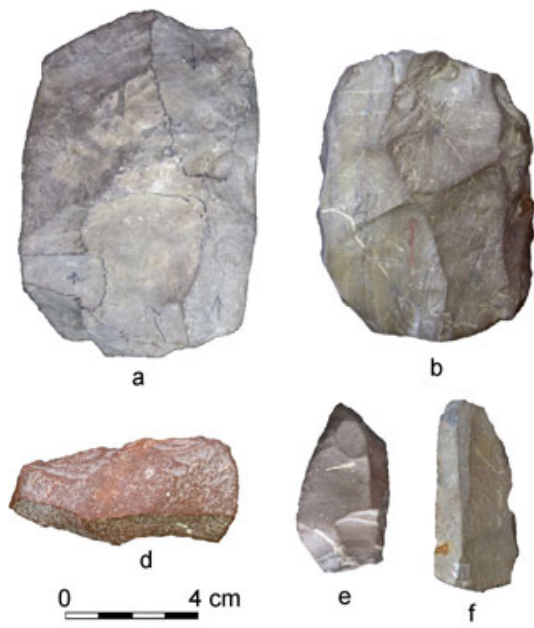

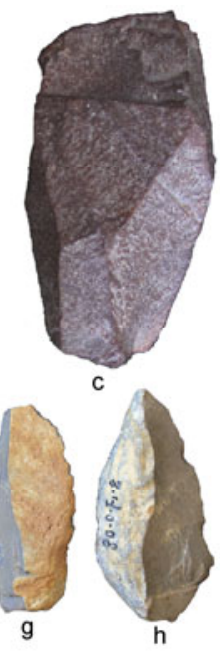

b

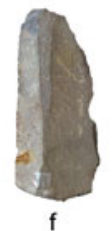

flaking (Figure 3c). Four scars can be recognized on the flaking surface, of which the maximum is $57.3 \mathrm{~mm} \times 34.6$ $\mathrm{mm}$. The two opposite platforms are all retouched and the platform angles are $72^{\circ}$ and $79^{\circ}$.

One of the cortical faces $(62.09 \mathrm{~mm} \times 26.09 \mathrm{~mm})$ bears 8 lines, clearly visible to naked eyes, which were engraved into the thick cortex (Figure 3a,b). All the incisions are closely perpendicular to the long axis of the core. Two incisions are crossed and others are parallel lines. With the exception of the rightmost line, these incisions almost extend to the ridge which is constituted by the two cortical surfaces (about $90^{\circ}$ in intersection angle) and two of them (Lines 2 and 7) even extend to the other cortical surface (Figure 3e).

In order to clarify the details of the incisions and to get more data characterizing the form of the lines, we used a KEYENCE VHX-600 Digital Microscope to observe the incisions. Also we reconstructed the 3D images of the incisions using the microscope. This new method and technology provides more information than observations by the naked eye.

First, we found several patinated and erosions traces that stained part of the incisions (Figure 3d). This suggests that a post-depositional process occurred after the piece was incised. It also proves that the incisions originated not from recent behavior during or after the excavation. All the 8 grooves are very straight and the incisions are continuous without breaks, implying each of them was incised once and in a short time. We measured the length, depth and width of the incisions at various points. The results are displayed in Figure $3 \mathrm{e}$ and Table 2. L2 is the longest and L8 is the shortest among all the incisions; they are 25.15 and $11.2 \mathrm{~mm}$ respectively. Although most of the incisions are quite light, they do not reach the limestone underlying the cortical cover. The core bears scar patterns that are characteristic of bi-directional
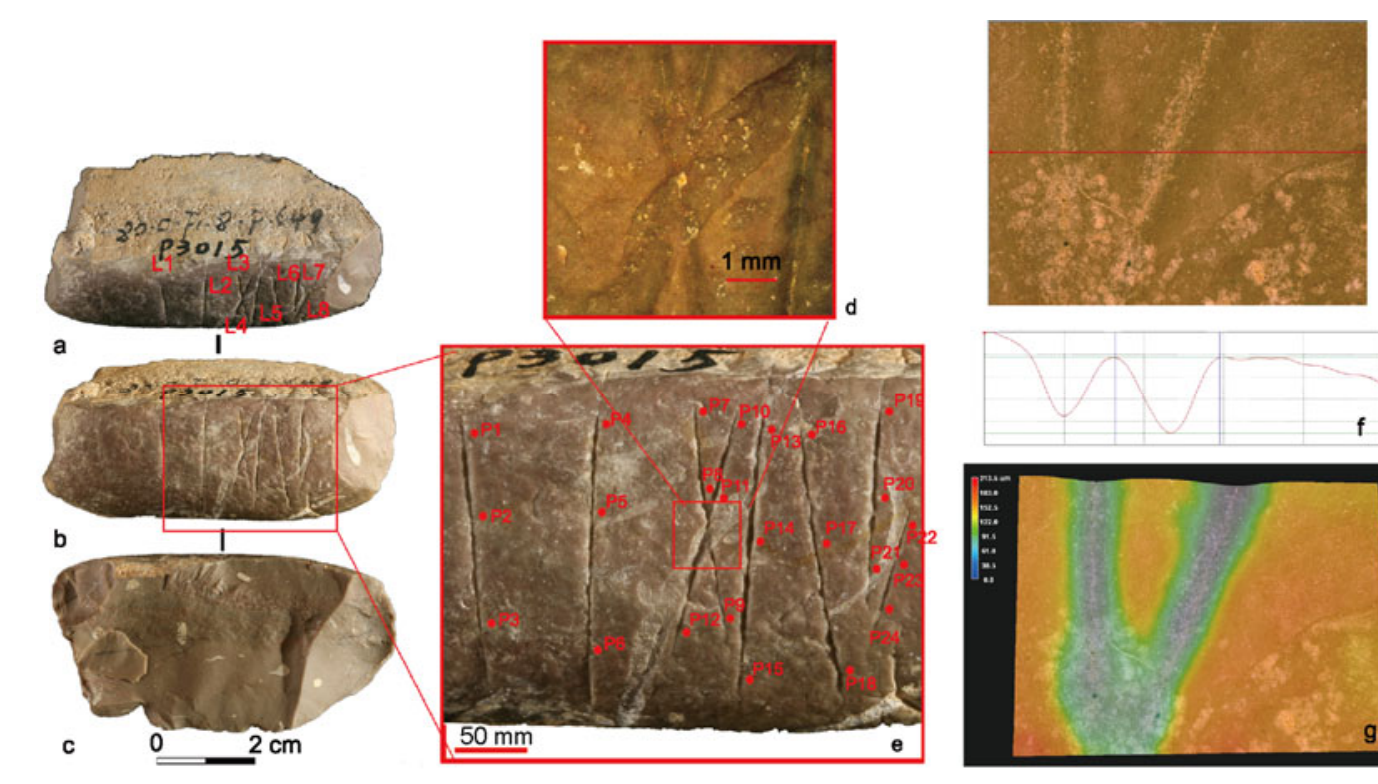
$68.2 \mathrm{~mm} \times 35.57 \mathrm{~mm} \times 22.7 \mathrm{~mm}$ in maximum dimension, the original size of which is difficult to estimate (Figure $3 \mathrm{a}-\mathrm{c})$. The core has three surfaces, consisting of one flaking surface and two cortex surfaces. The three surfaces form a triangular shape in cross-section. The flaking surface of the

The lithic industry from SDG1 has the features of Early similar to assemblages from the adjacent Mongolian and Altai regions which are dated to $30-40 \mathrm{ka} \mathrm{BP}$ [31].

\section{Engraved artifact}

The engraved artifact is a core made on siliceous limestone,

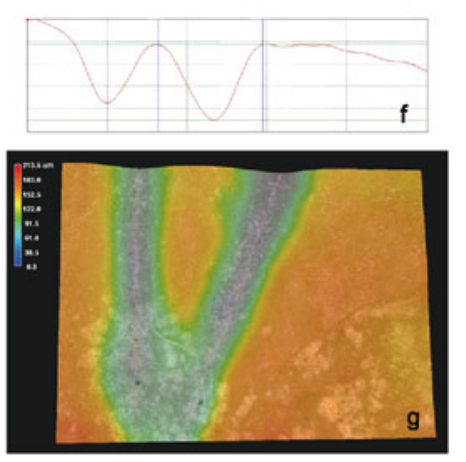

Figure 3 The engraved core and details of incision showed in resolution images and 3D image. a, b, Engraved face; c, flaking face; d, patination and erosion traces; e, high resolution image of incisions; f, red dots indicate points at which line widths and depths were measured; measured depth and width at P11; $\mathrm{g}, 3 \mathrm{D}$ image of P11. 
Table 2 Measurements of the incisions and lines ( $\mathrm{mm}$ )

\begin{tabular}{|c|c|c|c|c|c|c|}
\hline Line No. & Length & Point No. & Depth & Width & $\mathrm{AD}^{\mathrm{a})}$ of lines & $\mathrm{AW}^{\mathrm{b})}$ of lines \\
\hline \multirow[b]{2}{*}{$\mathrm{L} 1$} & \multirow[b]{2}{*}{19.6} & $\mathrm{P} 1$ & 0.138 & 2.255 & \multirow[b]{2}{*}{0.114} & \multirow[b]{2}{*}{1.791} \\
\hline & & $\mathrm{P} 2$ & 0.126 & 2.196 & & \\
\hline \multirow{3}{*}{ L2 } & \multirow{3}{*}{25.15} & $\mathrm{P} 4$ & 0.160 & 1.019 & \multirow{3}{*}{0.161} & \multirow{3}{*}{0.995} \\
\hline & & P5 & 0.154 & 1.098 & & \\
\hline & & P6 & 0.169 & 0.868 & & \\
\hline \multirow{3}{*}{ L3 } & \multirow{3}{*}{18.88} & $\mathrm{P} 7$ & 0.086 & 0.690 & \multirow{3}{*}{0.116} & \multirow{3}{*}{0.845} \\
\hline & & P8 & 0.152 & 0.879 & & \\
\hline & & P9 & 0.109 & 0.965 & & \\
\hline \multirow{3}{*}{ L4 } & \multirow{3}{*}{17.77} & $\mathrm{P} 10$ & 0.053 & 0.398 & \multirow{3}{*}{0.102} & \multirow{3}{*}{0.807} \\
\hline & & P11 & 0.144 & 0.798 & & \\
\hline & & $\mathrm{P} 12$ & 0.107 & 1.225 & & \\
\hline \multirow[t]{2}{*}{ L5 } & \multirow[t]{2}{*}{19.27} & P14 & 0.254 & 1.441 & \multirow[t]{2}{*}{0.177} & \multirow[t]{2}{*}{1.247} \\
\hline & & $\mathrm{P} 15$ & 0.145 & 1.247 & & \\
\hline \multirow{3}{*}{ L6 } & \multirow{3}{*}{20.96} & P16 & 0.060 & 0.641 & \multirow{3}{*}{0.155} & \multirow{3}{*}{0.988} \\
\hline & & P17 & 0.155 & 1.301 & & \\
\hline & & P18 & 0.249 & 1.022 & & \\
\hline \multirow{3}{*}{ L7 } & \multirow{3}{*}{14.7} & P19 & 0.074 & 0.406 & \multirow{3}{*}{0.109} & \multirow{3}{*}{0.945} \\
\hline & & $\mathrm{P} 20$ & 0.201 & 1.403 & & \\
\hline & & $\mathrm{P} 21$ & 0.053 & 1.025 & & \\
\hline \multirow{3}{*}{ L8 } & \multirow{3}{*}{12.41} & $\mathrm{P} 22$ & 0.076 & 0.733 & \multirow{3}{*}{0.081} & \multirow{3}{*}{0.991} \\
\hline & & $\mathrm{P} 23$ & 0.051 & 0.771 & & \\
\hline & & $\mathrm{P} 24$ & 0.117 & 1.468 & & \\
\hline Mean & & & 0.127 & 1.076 & & \\
\hline
\end{tabular}

a) AD: average depth; b) AW: average width.

deepest incision is $\mathrm{P} 14$, which is $0.254 \mathrm{~mm}$, and the deepest line is L5 with an average depth of $0.177 \mathrm{~mm}$. The widest line is L1 where the average width is $1.791 \mathrm{~mm}$. Although the lines exhibit some internal variability in width and depth, this is not obviously patterned. For example, the depths of P10 and P21 are both $0.053 \mathrm{~mm}$, but the widths are 0.398 and $1.025 \mathrm{~mm}$, respectively.

Second, there are many siliceous limestones having natural surface flaws in SDG1. Comparing the incised lines of the engraved core and the natural flaws of a pebble from SDG1 in 3D, we find they are completely different in the shape of the section. The incised line is V-shape, while the natural flaw is U-shape (Figure 4). Also, the natural flaws are more variable in depth than the incised lines which are mainly concentrated between $0.1-0.2 \mathrm{~mm}$. Besides, we found the natural flaws are often tracing the internal joints of pebble. All these support our argument that the incisions on the artifact are not naturally-caused. Additionally, the siliceous limestone is harder than organic materials such as bone, antler or ivory. Animal-induced damage could therefore not produce such deep grooves and the hardness of the siliceous limestone is less attractive for gnawing and chewing. Also, the patterns of grooves are not similar to the irregular patterns of carnivore gnawing traces [32]. Another possibility for the production of grooves is post-depositional phenomenon like trampling [33]. The trampling traces are commonly all random and with no clear orientations. But the incisions on the SDG1 core are almost all closely perpendicular to the long axis of core and two of them (L3 and L4) are crossed. Except for the eight lines, no more obvious grooves were observed. All the features of the engraved core of SDG1 are contrary to the characteristics of trampling. So we exclude the possibility of trampling as well. However, when other causes except human behaviors are rejected, there is still a question, i.e. if it is representative of intentional behavior or unintentional by-products? The engraved object of SDG1 is a small core. The size and mass weakens the interpretation that it was an anvil or cutting board which would have been possible surfaces for leaving unintentional marks by humans.

Finally, combining all these features, we suggest that the incisions were made by an intentional behavior and were probably of a non-utilitarian character.

\section{Discussion and conclusion}

Questions in the debates on "modern human behavior" are 

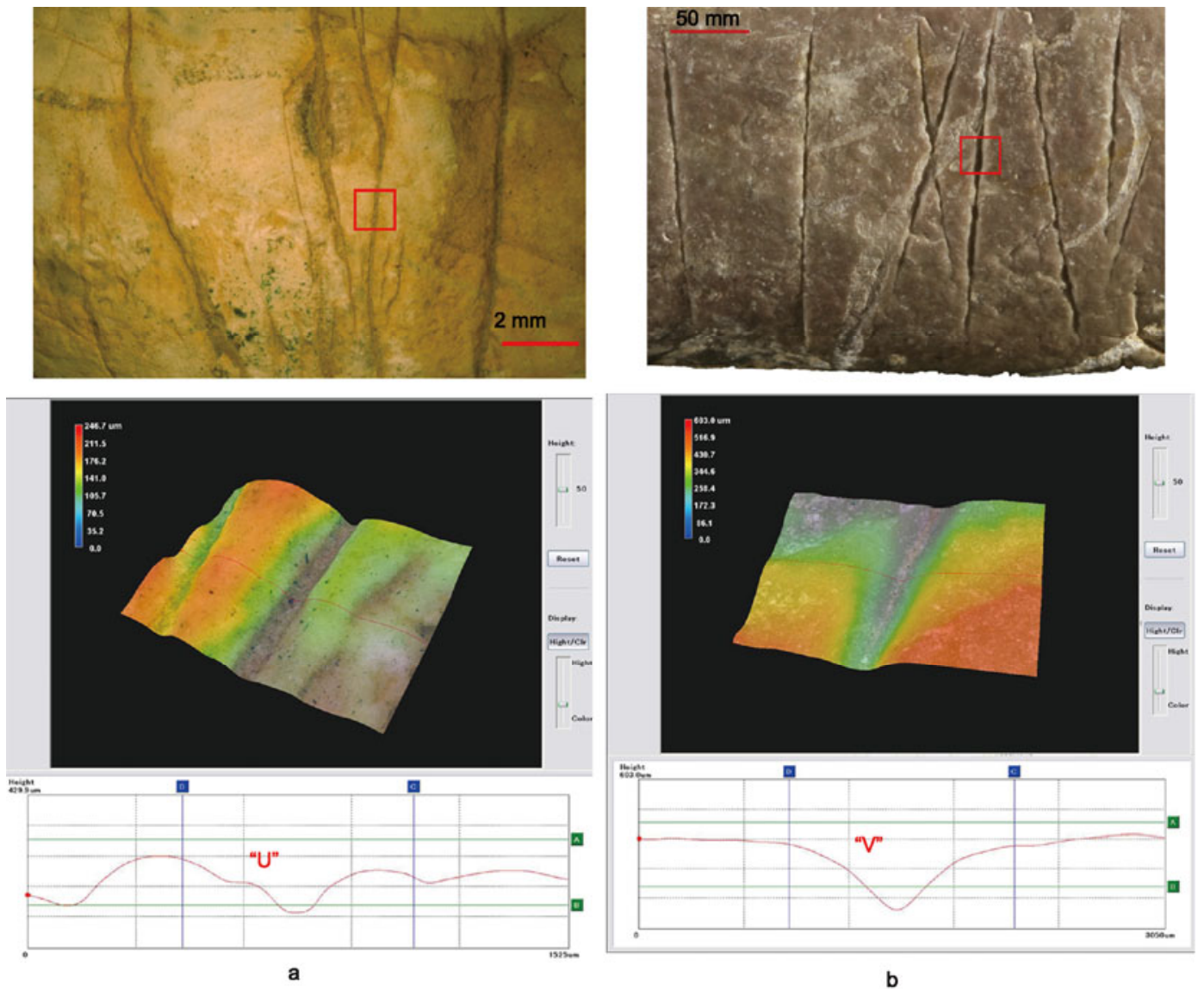

Figure 4 Comparison of section shape between natural flaws and intentional incision. a, Natural flaw with U-shape; b, intentional incision with V-shape.

whether the appearance of modern human behavior was a revolution, whether it proceeded by gradual evolutionary changes or saltation, and whether it is restricted only to Homo sapiens [34]. Whatever kinds of criteria are seen as the evidence for proving so-called "behaviorally modern" behavior, symbol and cognition are always the foci. Many scholars use engraved objects for analyzing the cognitive ability of ancient peoples. Although they infer that engraved objects are relevant to language, symbolism, art [5,6], and even lunar calendars $[4,35]$, the interpretation of these engraved objects is still quite open.

It is hard to say that the incision lines of the core in SDG1 constitute an abstract or depictional image like the engraved bones, pebbles and antlers from Aurignacian to Magdalenian period of Western Europe [4], even the earliest engraved ochre from Blombos Cave [8] and the engraved ivory from Xinglongdong cave [16]. Considering the object was used as a core for knapping which is different from most of other engraved objects without more human behavior except incision, that is means the core is not especially for engraving, we suggest the incisions on the core of SDG1 should not be seen as decoration. But indeed, the formation of incision lines through a series of intentional actions strongly implies an element of design. Though we cannot be sure of the function of these incisions, the straight shape of each line shows that it was incised once in a short time interval without repeated cutting, implying the possibility of a counting or recording at that time. Furthermore, this indicates the possible existence of complex communicative systems such as language.

In China, engraved objects from Pleistocene contexts were rarely reported. Until now, the earliest engraved object is found in Xinglongdong cave, South China. This is an engraved ivory and the U-series dating is around 120-150 ka BP [16]. In North China, Pei [36] first found an engraved antler from Upper Cave of Zhoukoudian site. You [14] reported an engraved bone from the Shiyu site which is thought to be about 28-32 ka BP. Bednarik [15,37] reported an engraved antler from Longgu cave which is about $13065 \pm 270$ a BP. But the nature of these artifacts is still debated and further analysis is needed $[15,17]$. Hence, it is too early to determine whether the non-utilitarian objects are representative of a succession of behaviors or whether the evidence from China supports any particular scenario about the emergence of modern human behavior. In any case, it cannot be denied that in the Early Late Paleolithic of NW China, hominids in SDG1 had considerably evolved cognitive capacities or modern human behavior [38]. 
The authors thank Dr. Mei Huijie for the excellent photographs, as well as Dr. Zhang Xiaoling and Prof. Qi Guoqin for their useful advices. Many thanks to Dr. Gong Tao and Dr. Lynne Schepartz who helped with polishing the English. Also thanks to Prof. Robert Bettinger, Dr. Loukas Barton and Dr. Christopher Morgan who discussed the age and stratum of SDG1 and provided the latest ${ }^{14} \mathrm{C}$ age. Thanks to Prof. Erella Hovers who provided important references. This work was supported by the Strategic Priority Research Program of the Chinese Academy of Sciences (XDA05130202), the Knowledge Innovation Program of the Chinese Academy of Sciences (KZCX2-YW-Q1-04), the Special Basic Research Project (2007FY110200) and the National Basic Research Program of China (2010CB950203).

1 McBrearty S, Brooks A S. The revolution that wasn't: A new interpretation of the origin of modern human behavior. J Hum Evol, 2000, 39: 453-563

2 d'Errico F. The invisible frontier: A multiple species model for the origin of behavioral modernity. Evol Anthr, 2003, 12: 188-202

3 Henshilwood C S, Marean C W. The origin of modern human behavior. Curr Anthropol, 2003, 44: 627-651

4 Marshack A. Cognitive aspects of Upper Paleolithic engraving. Curr Anthropol, 1972, 13: 445-477

5 Marshack A. Some implications of the Paleolithic symbolic evidence for the origin of language. Curr Anthropol, 1976, 17: 274-282

6 d'Errico F, Henshilwood C, Lawon G, et al. Archaeological evidence for the emergence of language, symbolism, and music-An alternative multidisciplinary perspective. J Worl Preh, 2003, 17: 1-70

7 Henshilwood C S, d'Errico F, Watts I. Engraved ochres from the Middle Stone Age levels at Blombos Cave, South Africa. J Hum Evol, 2009, 57: 27-47

8 Henshilwood C S, d'Errico F, Yates R, et al. Emergence of modern human behavior: Middle Stone Age engravings from South Africa. Science, 2002, 295: 1278-1280

9 Hovers E, Vandermeersch B, Bar-Yosef O. A Middle Palaeolithic engraved artefact from Qafzeh Cave, Israel. Rock Art Res, 1997, 14: 79-87

10 Hovers E. Art in the Levantine Epi-Paleolithic: An engraved pebble from a Kebaran site in the Lower Jordan valley. Curr Anthropol, 1990, 31: 317-322

11 Marshack A. A middle Paleolithic symbolic composition from the Golan Heights: The earliest known depictive image. Curr Anthropol, 1996, 37: 357-365

12 Mackay A, Welz A. Engraved ochre from a Middle Stone context at Klein Kliphuis in the western Cape of South Africa. J Arc Sci, 2008, 35: 1521-1532

13 Marshack A, Bandi H G, Christensen J, et al. Upper Paleolithic symbol systems of the Russian Plain: Cognitive and comparative analysis. Curr Anthropol, 1979, 20: 271-311

14 You Y Z. Preliminary study of a Palaeolithic bone engraving. Kexue Tongbao, 1984, 29: 80-82

15 Bednarik R G. The Pleistocene art of Asia. J Worl Preh. 1994, 8: 351-375

16 Gao X, Huang W B, Xu Z Q, et al. 120-150 ka human tooth and ivory engravings from Xinglongdong Cave, Three Gorges Region, South China. Chin Sci Bull, 2004, 49: 175-180

17 Norton C J, Jin J H. The evolution of modern human behavior in East
Asia: Current perspectives. Evol Anthr, 2009, 18: 247-260

18 Gao X, Norton C J. A critique of the Chinese 'Middle Paleolithic'. Antiquity, 2002, 76: 397-412

19 Ningxia Provincial Institute of Archaeology. Shuidonggou-1980 Excavation Report (in Chinese). Beijing: Science Press, 2003

20 Guan Y, Gao X, Wang H M, et al. Spatial analysis of intra-site use at a Late Paleolithic site at Shuidonggou, Northwest China. Chin Sci Bull, 2011, 56: 3457-3463

21 Wang $\mathrm{H} \mathrm{M}$, Pei S W, Ma X L, et al. A preliminary report on the excavations of Shuidonggou Localities 3, 4, 5 in Ningxia (in Chinese). Acta Anthropol Sin, 2007, 26: 206-221

22 Boule M, Breuil H, Licent E, et al. Le Paleolithique de la Chine. Paris: Archives de l'institut de Paleontologie Humaine, 1928, 4: 1-138

23 Jia L P, Gai P, Li Y X. The new material of Shuidonggou Paleolithic site (in Chinese). Vertebrata Palasiatica, 1964, 8: 75-83

24 Zhou K, Hu J. Environment and stratigraphy at the Shuidonggou site (in Chinese). Acta Anthropol Sin, 1988, 7: 263-269

25 Liu D C, Chen F Y, Zhang X L, et al. Preliminary comments on the Paleoenviroment of the Shuidonggou Locality 12 (in Chinese). Acta Anthropol Sin, 2008, 27: 295-303

26 Gao X, Yuan B, Pei S, et al. Analysis of sedimentary-geomorphologic variation and the living environment of hominids at the Shuidonggou Paleolithic site. Chin Sci Bull, 2008, 53: 2025-2032

27 Gao X, Li J, Madsen D B, et al. New ${ }^{14} \mathrm{C}$ dates for Shuidonggou and related discussions (in Chinese). Acta Anthropol Sin, 2002, 21: 211218

28 Liu D C, Wang X L, Gao X, et al. Progress in the stratigraphy and geochronology of the Shuidonggou site, Ningxia, North China. Chin Sci Bull, 2009, 54: 3880-3886

29 Li X G, Liu G L, Xu G Y, et al. ${ }^{14} \mathrm{C}$ dating to report(PV)I (in Chinese). In: ${ }^{14} \mathrm{C}$ Geochronology Group of Quaternary Committee, ed. Proceedings of Quaternary Glacier and Quaternary Geology (Series 4). Beijing: Geological Publishing House, 1987. 16-38

30 Chen T M, Yuan S X, Gao S J. The study on Uranium-series dating of fossil bones and an absolute age sequence for the main palaeolithic sites of North China (in Chinese). Acta Anthropol Sin, 1984, 3: 259-269

31 Brantingham P J, Krivoshapkin A I, Li J Z, et al. The initial Upper Paleolithic in Northeast Asia. Curr Anthropo, 2001, 42: 735-746

32 Binford L R. Bones: Ancient Men and Modern Myths. New York: Academic Press, 1981

33 Shea J J, Klenck J D. An experimental investigation of the effects of trampling on the results of lithic use wear analysis. J Archaeol Sci, 1993, 20: 175-194

34 d'Errico F, Stringer C B. Evolution, revolution or saltation scenario for the emergence of modern cultures? Phil Trans R Soc B, 2011, 366: 1060-1069

35 d'Errico F. Palaeolithic lunar calendars: A case of wishful thinking. Curr Anthropo, 1989, 30: 117-118

36 Pei W C. A preliminary report on the Late Paleolithic cave of Choukoutien. Bull Geol Soc Chin, 1934, 13: 327-358

37 Bednarik R G. Paleolithic art found in China. Nature, 1992, 356: 116

38 Guan Y, Gao X, Li F, et al. Modern human behaviors during the late stage of the MIS3 and the broad spectrum revolution: Evidence from a Shuidonggou Late Paleolithic site. Chin Sci Bull, 2012, 57: 379384

Open Access This article is distributed under the terms of the Creative Commons Attribution License which permits any use, distribution, and reproduction in any medium, provided the original author(s) and source are credited. 